\title{
El Acuerdo de Paz de La Habana. Un cambio institucional ambicioso con una estrategia dudosa*
}

\author{
Julián Esteban García Romero (Colombia)**
}

\section{Resumen}

En este artículo se analizan las imbricaciones entre cambio institucional, conflicto y poder político en el sistema presidencialista colombiano, tomando como estudio de caso los puntos de Reforma Rural Integral y Participación Política del Acuerdo de Paz de La Habana durante el Plebiscito por la Paz y el Fast Track. A partir del enfoque del neoinstitucionalismo sociológico, el cual permite analizar las instituciones incrustadas en la cultura y la estructura social, se analiza por qué el Acuerdo de Paz de La Habana es un cambio institucional y cuáles son los cambios proyectados. Algunos hallazgos indican que los potenciales cambios en las reglas políticas y en el acceso y uso de la tierra deben considerarse cuidadosamente dentro de configuraciones institucionales más amplias y sedimentadas históricamente, ya que, aunque el cambio institucional buscaba modificar los arreglos de poder en las instituciones, no se tuvo en cuenta el arraigo de estos en la estructura social y la cultura.

\section{Palabras clave}

Instituciones Políticas; Proceso de Paz; Acuerdo de Paz; Reforma Política; Reforma Agraria; Colombia.

Fecha de recepción: octubre de 2018

- $\quad$ Fecha de aprobación: abril de 2019

\section{Cómo citar este artículo}

García Romero, Julián Esteban. (2019). El Acuerdo de Paz de La Habana. Un cambio institucional ambicioso con una estrategia dudosa. Estudios Políticos (Universidad de Antioquia), 55, pp. 182-204. http://doi.org/10.17533/udea.espo. n55a09

\footnotetext{
* Este artículo es resultado del curso Regímenes de Acumulación y Ciudadanía de la maestría en Sociología Política de la Flacso-Ecuador. Agradezco a Franklin Ramírez por sus comentarios, así como a los pares evaluadores y al equipo editorial de la revista por sus acertadas observaciones y sugerencias. ** Politólogo. Antropólogo. Candidato a magíster en Sociología Política Flacso-Ecuador. Correo electrónico: estebangarcia0409@gmail.com - Orcid: http://orcid.org/0000-0003-0818-6818
} 


\title{
The Havana Peace Agreement. An Ambitious Institutional Change with a Dubious Strategy
}

\begin{abstract}
This research analyses the imbrications among institutional change, conflict, and political power in the Colombian presidential system, taking as a case study the points of the Integral Rural Reform and Political Participation of the Havana Peace Agreement, during the plebiscite for peace and the «Fast Track» implementation in order to approve the law changes in the Congress. The question that guides the analysis is the following: Why do the Havana Peace Agreement implies an institutional change and what are the changes projected by it? The study applies a sociological neo-institutionalism approach, which allows the analysis of the institutions embedded in the culture and social structure. The methodological strategy used is the qualitative case study. The analysis shows that the potential changes in political rules and in the access and use of land must be carefully considered within broader and historically sedimented institutional configurations. The institutional change sought to modify the power arrangements in the institutions; however, their roots in the social structure and culture were not taken into account in order to effect this modification.
\end{abstract}

\section{Keywords}

Political Institutions; Peace Process; Peace Agreement; Political Reform; Agrarian Reform; Colombia. 


\section{Introducción}

Para disciplinas como la Antropología y la Sociología las instituciones son un fenómeno de vieja data el cual nunca han desestimado, sin embargo, para la Ciencia Política y la Economía a partir de la década de 1960 se empieza a dar un auge de estudios sobre la relación entre instituciones, gobernanza, desarrollo, democracia, entre otros. Diferentes vertientes de la política comparada y la economía han realizado innumerables investigaciones sobre estos temas. En la actualidad el «giro institucional» es ampliamente compartido, aunque las posturas teóricas de algunas disciplinas y ramas de estas guarden sus diferencias analíticas en la concepción de las instituciones.

El presente texto tiene como objetivo hacer un aporte interdisciplinario a las investigaciones sobre las imbricaciones entre cambio institucional, conflicto y poder político en sistemas presidencialistas, en donde el juego político entre el Ejecutivo, el Legislativo y el Judicial afectan la implementación del cambio que representan los puntos de Reforma Rural Integral y Participación Política del Acuerdo de Paz de La Habana.

El problema de investigación es cómo el cambio institucional que busca

[184] transformar la distribución de poder en una sociedad profundamente desigual genera un conflicto político entre fuerzas sociales que buscan la modernización, la democratización y el desarrollo, y otras que ven en este proceso un peligro para el balance del poder de clase y el sistema de valores que los sostiene. Las conexiones y superposiciones entre cambio institucional, poder político y conflicto varían desde la Mesa de Negociación en La Habana, pasando por el Plebiscito por la Paz y finalmente por los debates en el Senado, dando como resultado reacomodos de las fuerzas sociales y ajustes a lo pactado. Todo esto se enmarca en las dinámicas del presidencialismo colombiano, sistema que influye en el juego político al interior de sus instituciones políticas.

Partiendo del nuevo institucionalismo sociológico y tomando algunas nociones de los estudios sobre sistemas de partidos de la Ciencia Política, se profundiza sobre las tensiones y resistencias que se generan en la cultura, en la estructura social y en las instituciones políticas - como el Senadoal iniciar un proceso de cambio institucional. El nuevo institucionalismo sociológico estudia las instituciones desde la sociología clásica, contemporánea y económica como enfoques que permiten entender a las instituciones incrustadas en la cultura y la estructura social. De esta forma, dejan de lado 
las concepciones economicistas de las instituciones para darle un giro hacia la raíz social de las mismas. En este giro el contexto, entendido como las relaciones sociales y la estructura social, toma relevancia al analizar por qué el trasplante de instituciones de un contexto a otro no tiene los resultados esperados por quienes toman las decisiones y formulan las políticas, ya que dimensiones como la cultural, en donde las normas y los valores se originan, $y$ las estructuras sociales, donde reside el poder, cambian lentamente.

Para llevar a cabo este estudio se aborda el caso del Acuerdo de Paz de La Habana, con el que el gobierno del entonces presidente Juan Manuel Santos y la guerrilla de las FARC-EP pactaron una serie de reformas en diferentes aspectos para lograr una paz estable y duradera, específicamente las reformas contempladas en los puntos 1 y 2 , en los cuales se establecen nuevas instituciones y reglas de juego que buscan el acceso a la tierra, el desarrollo de regiones marginalizadas y la inclusión y participación de sectores sociales en la arena pública, consideradas como las causas históricas del conflicto armado en Colombia (Vega, 2015; Gutiérrez, 2015). Separar estos dos puntos del resto del Acuerdo tiene fines analíticos, ya que permite rastrear detalladamente los cambios que tuvieron y, sobre todo, el malestar que generado por lo acordado.

Este tema es importante por dos motivos: primero, porque actualmente se está dando un retroceso o una parálisis en la implementación del Acuerdo de Paz, fenómeno que más allá de obedecer a asuntos como el cambio de gobierno y su falta de voluntad política para la implementación, tiene de trasfondo el conflicto político que genera el cambio institucional. En este sentido, la presente investigación llama la atención sobre la necesidad de estudiar ese conflicto mediante el juego político en el Congreso — Senado y Cámara de Representantes - y la Corte Constitucional en momentos de transición, en donde la correlación de fuerzas puede facilitar la implementación de cambios en la distribución del poder o contra reformas que profundicen la desigualdad.

El segundo motivo es que hay una vacancia empírica. Si bien se han realizado varias investigaciones sobre la capacidad institucional del Estado colombiano y su relación con la consolidación de la democracia y el desarrollo que propone el Acuerdo de Paz, estos estudios se focalizan en la capacidad institucional de los municipios priorizados y reflexionan sobre el modelo de Estado que podría darse al implementar el Acuerdo (Arévalo, 2014; Trejos 
y Tuirán, 2017). También están las investigaciones de tipo más teórico, que desde el nuevo institucionalismo económico (NIE) y el nuevo institucionalismo normativo (NIN) buscan entender los procesos de implementación de los acuerdos de paz y la manera en que este tipo de operaciones y estrategias pueden llegar a construir y desarrollar instituciones (Zamudio y Culebro, 2013). Sin embargo, no hay investigaciones sobre el Acuerdo como un cambio institucional y el juego político que se desencadena, esto es una deuda no saldada. El más cercano ha sido Álvaro Albán (2017), quien señala que hay una fuerte capacidad de cierto orden social para resistirse a los cambios institucionales.

Del cúmulo de investigaciones revisadas, la presente se inscribe en la línea de Laura Zamudio y Jorge Culebro (2013) y Álvaro Albán (2017), en cuanto que toma elementos teóricos de una de las corrientes del nuevo institucionalismo para analizar el conflicto político en torno al cambio que implica el Acuerdo de Paz. El nuevo institucionalismo normativo permite observar la forma en que el comportamiento y las decisiones de estos actores son afectados por marcos institucionales que han sido construidos de forma histórica, y que los actores también son capaces de modificar estas instituciones (Zamudio y Culebro, 2013). No obstante, ese nuevo institucionalismo no se fija en el peso de las relaciones sociales, la estructura social y el sistema de valores para los procesos de cambio, lo cual es clave dado el trasfondo del conflicto social y armado en Colombia. No tener en cuenta estos asuntos es un desatino.

Por otra parte, el enfoque sociológico entiende la arquitectura institucional como un producto de relaciones sociales asimétricas sedimentadas en la historia, son clave el papel de la cultura y de la estructura social (Albán, 2017). No obstante, dentro de los desafíos que debe sortear el Acuerdo para generar una transformación en profundidad del ordenamiento institucional, Albán (2017)deja de lado el proceso de negociación de estos cambios en la refrendación popular y al interior del Senado en un sistema presidencialista, en donde asuntos como las alianzas, los bloques de mayorías, las reglas de juego, los incentivos, las relaciones de poder y los tipos de actores desempeñan un papel central; tampoco hace un seguimiento a la modificación de los puntos del Acuerdo y cómo estas reflejan el conflicto político, se limita a identificar las fuerzas que se oponen al cambio pero no la forma en que se materializa esa resistencia. 
La estrategia metodológica que se usa en este estudio de caso es cualitativa, la cual tiene como característica básica que aborda de forma intensiva una unidad, que puede referirse a una persona, una familia, un grupo, una organización o una institución. Es una investigación ideográfica que implica la descripción amplia y profunda del caso, sin el propósito de partir de una hipótesis o teoría rígida. Dentro de las múltiples tipologías de los estudios de caso, se enmarca en aquel que estudia la variación de una unidad singular a lo largo de un corto periodo de tiempo. Se utiliza el caso del cambio institucional en los puntos 1 y 2 del Acuerdo de Paz con fines tanto descriptivos como explicativos. Por su parte, la credibilidad de la investigación en este método se asegura de forma analítica, es decir, el modelo teórico puede servir para analizar fenómenos similares y se sustenta mediante la explicitación de los pasos teóricos y metodológicos de la investigación.

Se parte de la hipótesis flexible de que el Acuerdo de Paz de La Habana es un cambio institucional, es decir, es una modificación profunda de los planos legales y normativos bajo los que operan los actores, que involucra la creación y modificación de una serie de instituciones para la modernización, democratización y el desarrollo de Colombia. Este cambio implica reformas políticas y rurales que dan como resultado nuevas reglas de juego, esto generó malestar en ciertos estamentos sociales, clases terratenientes, instituciones electorales y órganos legislativos y judiciales, ya que perderían ciertos privilegios. La resistencia a este cambio institucional que manifestó gran parte de la sociedad se puede sintetizar lo que señala Alejandro Portes y Lori Smith (2012): «imponer un conjunto de reglas formales sin simultáneamente reorganizar la distribución de poder que subyace a todo arreglo institucional es una estrategia muy dudosa» (p. 56), puesto que se presenta una disyuntiva entre las estructuras formales y las subyacentes prácticas y estructuras de poder más informales, tornando inefectivas las estructuras formales.

Las preguntas analíticas que guían este texto son las siguientes: ipor qué el Acuerdo de Paz de La Habana se puede concebir como un cambio institucional?, ¿cuáles son los cambios proyectados en dicho acuerdo?, ¿cómo fue el juego político en el periodo del Fast Track al interior del Senado? y ¿cómo variaron las imbricaciones entre cambio institucional, estructura social, cultura, poder político y conflicto? 


\section{Objetivos e instituciones del Acuerdo de Paz}

No hay duda de que «las instituciones importan», pero están sujetas al «problema del encaje social»: el hecho de que los intercambios humanos que las instituciones tratan de guiar afectan, a su vez, a estas instituciones (Granovetter, 2003, p. 240).

Al examinar lo pactado en el Acuerdo de Paz de La Habana, Ilama la atención los objetivos que tiene, ya que supondría la apertura de un nuevo capítulo de la historia de Colombia.

Se trata de dar inicio a una fase de transición que contribuya a una mayor integración de nuestros territorios, una mayor inclusión social -en especial de quienes han vivido al margen del desarrollo y han padecido el conflicto- $y$ a fortalecer nuestra democracia para que se despliegue en todo el territorio nacional y asegure que los conflictos sociales se tramiten por las vías institucionales, con plenas garantías para quienes participen en política (Gobierno y FARC-EP, 2016, p. 6).

Esto, a simple vista, es una labor titánica, teniendo en cuenta los niveles de concentración de la tierra, la violencia política y la pobreza que embarga al país. Precisamente, los objetivos del Acuerdo apuntan a lo que ambas partes identificaron como las condiciones que han facilitado la persistencia de la violencia en el territorio, sus causas históricas.

En aras de desarrollar a fondo las preguntas de investigación, hay dos puntos neurálgicos para demostrar por qué este Acuerdo implica un gran cambio institucional. El primero de ellos es la cuestión no resuelta de la propiedad sobre la tierra y, particularmente, su concentración; el segundo es la exclusión de ciertos sectores sociales en la participación de la vida política. El punto 1 contiene la política de desarrollo agrario integral que busca transformar la realidad del campo colombiano y brindar una mejor calidad de vida al campesinado, esto se materializa en la denominada Reforma Rural Integral: hacia un nuevo campo. Esta transformación estructural de la ruralidad pretende cerrar las brechas entre el campo y la ciudad, al proveer bienes y servicios públicos, estímulos a la producción campesina y presencia estatal en territorios marginalizados. 
El punto 2 contiene la política de participación y apertura democrática del Acuerdo de Paz, la cual tiene como pilares la apertura del sistema político a sectores excluidos, la participación política con garantías y el divorcio entre armas y política. La construcción y consolidación de la paz, en el marco del fin del conflicto, requiere de:

Una ampliación democrática que permita que surjan nuevas fuerzas en el escenario político para enriquecer el debate y la deliberación alrededor de los grandes problemas nacionales y, de esa manera, fortalecer el pluralismo y por tanto la representación de las diferentes visiones e intereses de la sociedad, con las debidas garantías para la participación y la inclusión política (Gobierno y FARC-EP, 2016, p. 7).

La implementación de este punto del Acuerdo contribuiría especialmente a la ampliación y profundización de la democracia, con garantías plenas para quienes participen en política. Así, un cambio institucional es una modificación profunda de los planos legales y normativos bajo los que operan los actores (Evans, 2006). En este sentido, los puntos 1 y 2 pueden ser vistos como parte de un cambio institucional, en cuanto buscan trastocar un conjunto de reglas formales sobre subyacentes prácticas y estructuras de poder más informales, son procesos de reformas estructurales en materia política y rural.

Para la democratización del acceso y uso adecuado de la tierra, el cual permita una mejor distribución de tierras para los habitantes del campo, se creó el Fondo de Tierras - 3 millones de hectáreas - y la formalización masiva de la propiedad rural -7 millones de hectáreas- En este punto también están los Programas de Desarrollo con Enfoque Territorial (PDET), que tienen como fin lograr la transformación estructural del campo y el ámbito rural. Todas estas instancias y figuras buscan cambiar la inequidad en el acceso a la tierra, lo cual traería nuevas formas de relacionamiento social en el campo, lo que es un gran cambio institucional, tanto por la nueva institucionalidad creada - Agencia Nacional de Tierras, Agencia de Renovación del Territorio y Agencia de Desarrollo Rural- como por el impacto que esta política de desarrollo agrario integral puede tener en los niveles de desigualdad, pobreza y concentración de la tierra en Colombia.

El punto 2 también representa un cambio en la participación política, la profundización de la democracia, de las instituciones políticas y sus reglas. 
Uno de sus pilares es el estatuto de oposición, el cual es una deuda histórica para la apertura democrática, ya que se buscan garantías para ejercer la oposición. Este estatuto no vino desde La Habana, sino que provino de una comisión en la que están representados todos los partidos y movimientos políticos. Otro pilar es la creación de las Circunscripciones Transitorias Especiales de Paz, las cuales significan una representación temporal de los territorios más invisibilizados en la Cámara de Representantes e independientes de las que ya se tienen representación en Senado y Cámara, y los partidos políticos ya existentes no podrán presentar candidatos, ya que se quiere privilegiar a las organizaciones y movimientos sociales. Para las reformas en la organización del régimen electoral se concertó la creación de una Misión Electoral Especial (MEE), con el fin de presentar recomendaciones para que el Gobierno tramite los ajustes normativos e institucionales necesarios que giren alrededor de tres dimensiones interrelacionadas: la arquitectura institucional de lo electoral, el sistema electoral propiamente dicho y la financiación de partidos y campañas.

Cada país produce su institucionalidad, la cual está atravesada por arreglos de poder, en este sentido, un cambio de esta envergadura en las reglas en materia política y rural generó que el juego de poder y la lucha política se dinamizara (Evans, 2006). Esto se materializó en la puja por la legitimidad de lo acordado en una sociedad altamente polarizada en donde sectores políticos más recalcitrantes en contra del acuerdo, como el partido Centro Democrático, asociaciones de ganaderos y empresarios agroindustriales con amplio apoyo popular, exigieron que lo acordado se refrendara (Semana, 2016, noviembre 25). El entonces presidente Santos vio en el plebiscito una oportunidad para que el proceso ganara legitimidad democrática, a pesar de que muchos expertos constitucionalistas afirmaron que esto no era innecesario y que en algunos sectores de las FARC-EP esta iniciativa no tenía mucha resonancia (Semana, 2016, marzo 10).

La victoria del No en el Plebiscito por la Paz generó reacomodos en el tablero del juego de poder, ya que en el panorama político nacional se vieron fortalecidos políticamente los sectores que apoyaron al No, especialmente el uribisimo de cara a la campaña presidencial de 2018. Si bien se llevó a cabo una renegociación en la cual se tomaron en cuenta algunos puntos de los partidarios del No, los críticos del Gobierno hicieron mucho énfasis en la contradicción inherente al desconocimiento de los resultados del plebiscito, 
ya que para ellos eran necesarios cambios más profundos. Esta contradicción y desconocimiento de los resultados fue recordada constantemente, moldeando la opinión pública (Basset, 2018). La falta de consenso frente a la paz negociada dejó al proceso de paz con un déficit de legitimidad política; a su vez, el pulso de fuerzas permitió entrever las superposiciones y relaciones entre cambio institucional, poder y conflicto político. La estrategia para implementar ese cambio institucional era inevitablemente vulnerable al reacomodo de las fuerzas, a la pérdida de legitimidad, a los costos políticos del plebiscito, a presiones y cambios externos:

La superficialidad de la imposición de formas institucionales es parte del problema: las «reformas» son impuestas en aquellos ámbitos organizacionales más fácilmente sujetos a la presión externa -las reglas formales de las organizaciones del sector público-. Estos son contextos institucionales rápidamente «movibles». Las arenas más inaccesibles y menos transparentes aunque fundamentales al funcionamiento de estas organizaciones, como las redes informales de poder y las rutinas operativas que producen outputs organizacionales efectivos, son ignoradas (Portes y Sensenbrenner, 2012, p. 10).

La derrota del Sí expresó asuntos como la debilidad de las alianzas políticas a lo largo del proceso de negociación, la distancia de la sociedad civil, la desconexión del Ejecutivo y los movimientos sociales y el alto poder de veto de determinados sectores. La renegociación del segundo acuerdo tomó cuarenta días, el cual se firmó el 26 de noviembre de 2016 y el Congreso en sesiones separadas lo aprobó (EI Tiempo, 2016, noviembre 16). En el tema de tierras, los líderes políticos del No señalaron que el Acuerdo debía respetar la legítima propiedad privada y reconocer la existencia de la producción empresarial a gran escala (El Tiempo, 2016, noviembre 17). El nuevo Acuerdo de Paz señala que «nada de lo establecido en el Acuerdo debe afectar el derecho constitucional a la propiedad privada» (Gobierno y FARC-EP, 2016, p. 13) y también hace explícita la coexistencia entre la agricultura campesina y la agricultura comercial a gran escala, promoviendo, además, la asociatividad entre ambas. Considero que la clase terrateniente que representa a los sectores más reacios en torno al Acuerdo de Paz, cuyas ideas radicales tienen resonancia en amplios sectores populares, vio en el triunfo del No una oportunidad para defender sus privilegios:

Las clases dominantes de los países rara vez renuncian voluntariamente a sus posiciones o a los recursos que les confieren poder. Casi siempre 
se produce una lucha en la que las ventajas de poseer cargos dan la delantera a las elites establecidas. Es por ello que ha sido tan difícil implementar políticas de reforma agraria, ante la oposición organizada de los terratenientes (Portes y Sensenbrenner, 2012, p. 15).

Las modificaciones hechas en este punto contaron con apoyo popular, gracias a las campañas de desinformación que tuvieron eco en el sistema de valores de la sociedad colombiana, permeado por el miedo y el odio (Rincón, 2018). Hubo toda una movilización política de las emociones en redes sociales, partidos políticos y medios de comunicación que influenciaron sectores sociales (Perilla, 2018). Los golpes a la distribución de poder que impone todo cambio institucional pueden causar una oposición general cuando los valores básicos en la dimensión cultural se mantienen inalterados, aunque estos cambios institucionales pueden llegar a propiciar en el tiempo modificaciones en dicho sistema de valores.

\section{El juego político durante el periodo de Fast Track}

El juego político puede contribuir a la estabilidad de las políticas públicas o conducir a grandes vaivenes. El juego político está determinado por las instituciones políticas propias de cada país, como el tipo de presidencialismo, las reglas del Congreso, etc. (Scartascini, Spiller, Stein, y Tommasi, 2011, p. 22).

Antes de desarrollar los argumentos de esta sección es necesario hacer una breve contextualización de lo que fue el mecanismo de vía legislativa conocido como Fast Track, el cual se gestó gracias a una reforma constitucional que se aprobó en junio de 2016 en el Congreso y tuvo el visto bueno de la Corte Constitucional. Se creó mediante el Acto Legislativo 01 del 7 de julio de 2016 para que el Congreso aprobara de manera abreviada y en trámite especial las normas y reformas constitucionales que requería la implementación del Acuerdo de Paz. Además, le otorgó facultades extraordinarias al entonces presidente Santos para expedir decretos con fuerza de ley, exclusivamente relacionados con el desarrollo del Acuerdo.

El periodo de Fast Track fue posterior al Plebiscito por la Paz y la renegociación del Acuerdo de Paz y se llevó a cabo entre diciembre de 2016 y noviembre de 2017. Este mecanismo planteó varias transformaciones en 
la aprobación de las reformas, lo cual, de por sí, fue un cambio institucional temporal, ya que redujo el número de debates requeridos por el procedimiento legislativo ordinario para aprobar proyectos de ley y proyectos de acto legislativo — que modifican la constitución-. En un principio ese Acto Legislativo por la Paz determinó que el Congreso no podía introducir ninguna modificación ni enmienda a los proyectos de ley presentados para implementar los acuerdos de paz con las FARC-EP que no tengan el aval del presidente, solo podría aprobarlos o no aprobarlos. No obstante, en mayo de 2017 la Sala Plena de la Corte Constitucional debatió los expedientes sobre dicho acto legislativo. Cabe recordar que este debate se dio debido a la demanda radicada por el entonces senador Iván Duque, del partido Centro Democrático, lo cual dio como resultado que el alto tribunal eliminara dos numerales claves $-\mathrm{H}$ y $\mathrm{J}-$ que se habían pactado en el Congreso. De esta forma, ya no fue necesario el aval del Ejecutivo para promover modificaciones a los proyectos de ley. Con esta decisión cualquier congresista que quisiera hacer un cambio a un proyecto de ley o a un acto legislativo que se presente por Fast Track podría hacerlo y su petición sería estudiada por el Congreso. También se tuvo que votar artículo por artículo y modificación por modificación, no siendo válida la votación en bloque de las propuestas. «Los cambios en los sistemas presidencialistas son dramáticos porque llevan una reorganización más grande del gobierno» (Scartascini et al., 2011, p. 35). Los sistemas presidenciales son rígidos y esta rigidez se caracteriza en situaciones en que los presidentes carecen de una mayoría de curules en el legislativo, lo cual genera poca estabilidad en las políticas y trabas en los planes de gobierno.

Este episodio fue el detonante del juego político que se avizoró en el Senado, ya que se pensaba que el Fast Track aumentaba los poderes constitucionales de tipo legislativo del Ejecutivo - poder de veto total o parcial, poder de aprobar decretos o declarar urgente un proyecto de ley(Scartascini et al., 2011); sin embargo, estos fueron restringidos por la decisión de la Corte Constitucional, lo que no se tenía previsto en la estrategia. Esta es una clara muestra de que en el presidencialismo colombiano el presidente no es el único actor en el proceso de formulación de políticas. La Corte, como institución política, tiene un peso significativo frente a los procesos de cambio institucional, un ejemplo de lo que se denomina «judicialización de la política» (Uprimny, 2007). La Corte Constitucional es un actor que da forma a las políticas de acuerdo con sus preferencias y las de algunos sectores 
políticos, esto hace parte del modelo neoconstitucional inaugurado con la Constituyente de 1991.

Entiendo muy esquemáticamente por judicialización de la política el hecho de que ciertos asuntos que tradicionalmente habían sido decididos por medios políticos, y que se consideraba que eran propios de la política democrática, empiezan a ser crecientemente decididos por los jueces, o al menos son fuertemente condicionados por decisiones judiciales, lo cual implica, a su vez, que muchos actores sociales empiezan a formular sus demandas en términos jurídicos y judiciales (Uprimny, 2007, p. 54).

El poder judicial en el presidencialismo colombiano no es independiente debido a las reglas de elección, puesto que los magistrados de la Corte Constitucional son elegidos por el Senado de la República para periodos individuales de ocho años, de ternas que le presenten el presidente de la República, la Corte Suprema de Justicia y el Consejo de Estado, lo cual implica que las acciones de la Corte representan los intereses de ciertos sectores. Se habla se la presión que deben ejercer los candidatos a magistrados en el Senado para asegurar su puesto, una suerte de «politización de la justicia». Esto implica que se den una serie de correlaciones de fuerza entre el Ejecutivo,

\section{[194] el Legislativo y el Judicial.}

Pese a la decisión de la Corte Constitucional, el Ejecutivo conservó sus poderes partidistas — grado de apoyo al presidente en el Congreso-, ya que, en teoría, tenía una bancada pro-paz numerosa en el Senado que le permitiría superar los impases que le podía generar el Centro Democrático como bloque de oposición a los acuerdos de paz junto al Partido Conservador. No obstante, esto no fue del todo como se tenía pensado, ya que jugaron muchos factores: primero, cabe recordar que debido a que Santos se distanció de las posturas del uribismo en su primer mandato (2010-2014), tuvo una pérdida de capital político que se vio reflejada en su apretado triunfo en las elecciones de 2014, cuando enfrentó a Oscar Zuluaga, candidato del Centro Democrático. Para la reelección de Santos en 2014 fue necesario que su partido —el Partido de la U— formara coaliciones con otros partidos como Cambio Radical, Partido Verde, Partido Liberal y el Polo Democrático, lo cual se tradujo en gabinetes ministeriales multipartidistas. Este fue uno de los factores que afectaron el comportamiento del voto legislativo y la capacidad del presidente para pasar su agenda por el Congreso, ya que los ministros encargados de ejercer presión y las ponencias en el Senado pertenecían a partidos con intereses diversos, lo cual afectó su desempeño. 
Gráfica 1. Conformación del Senado, periodo 2014-2018.

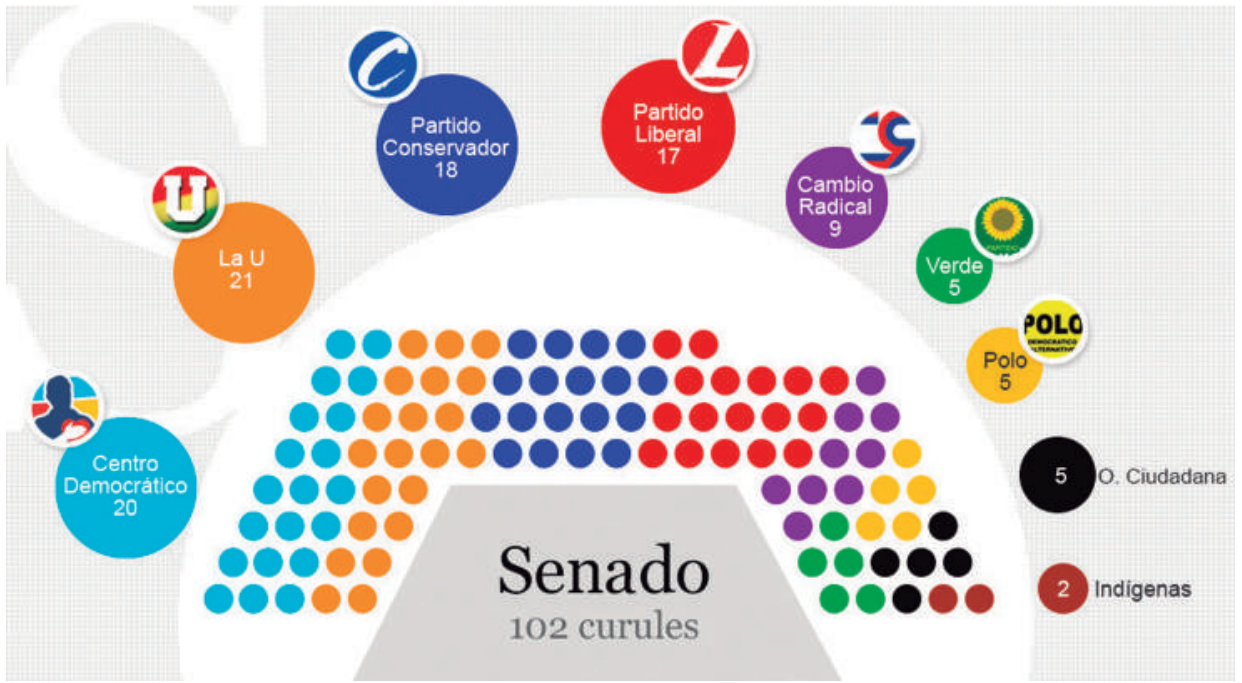

Fuente: tomado de Semana (s. f.).

Al consultar a miembros de las Unidades de Trabajo Legislativo (UTL) de senadores sobre los demás factores que influyeron en la aprobación de lo pactado en los puntos 1 y 2 del Acuerdo de Paz (quienes pidieron confidencialidad sobre sus nombres y el de sus jefes), coincidieron en que el poder partidista de Santos se deterioró, puesto que el tamaño de su bancada se fue reduciendo e imperó la desobediencia, esto último se ejemplifica más adelante. Lo primero se dio por tres razones: la primera de ellas fue la pérdida de apoyo por parte de senadores de partidos como el Verde y el Polo Democrático, al darse cuenta de que el Ejecutivo estaba intentando sutiles cambios al texto original de lo acordado en política rural, los cuales no estaban amparados en el Acuerdo de Paz. Este tipo de jugadas hicieron que se perdiera confianza en las intenciones del ejecutivo, a continuación, un extracto de la entrevista en donde se detalla lo señalado:

¿Cuáles factores cree usted que afectaron la aprobación del punto 1 en el Senado?

Pues uno de esos factores fue que el Gobierno, a través de la iniciativa legislativa que le permitía presentar proyectos con fuerza ley, metía micos [fuertes modificaciones], con la excusa de la implementación del Acuerdo. Por ejemplo, recuerdo el caso del Decreto Ley 902, que es la reglamentación de la Reforma Rural Integral, que no se termina 
Ilevando al Congreso, sino que es expedido como decreto de fuerza de ley. En el fondo, este Decreto 902 lo que buscaba era derogar disposiciones de la Ley 160, Ley de Reforma Agraria, y armonizar la Reforma Rural Integral con la Zidres [Zonas de Interés de Desarrollo, Rural, Económico y Social], que son zonas que formalizan baldíos de la nación para dárselas a empresarios en forma de comodatos o arriendo. Por eso los senadores de los partidos pro-paz empezaron a quitar su apoyo (comunicación personal, Andrea Lozano, asesora UTL, agosto 8, 2018).

Otros de los factores que incrementaron la pérdida de poder partidista fue la falta de unidad y cooperación del partido de gobierno y de algunos de su coalición, como el Liberal y Cambio Radical. La estabilidad de las políticas depende de la capacidad y habilidad de los actores políticos de acordar y hacer cumplir acuerdos más allá de la duración en el cargo de ciertos políticos (Scartascini et al., 2011). Este aspecto fue muy débil en la bancada pro-paz, ya que, según lo expuesto por los entrevistados, si bien al inicio del proceso de paz hubo un apoyo por parte de los partidos de la U, Cambio Radical y Liberal, al iniciar el proceso de debate para la aprobación de los proyectos de ley el apoyo no fue el mismo. El asesor del senador del Centro Democrático manifiesta que esto se debió a que de fondo el interés era que las FARC-EP se desmovilizaran y no que se implementara el Acuerdo de Paz. A continuación, otro fragmento de entrevista sobre este asunto:

¿Por qué la bancada del gobierno no actuó como bloque?

No hubo unidad en la bancada del gobierno, hubo incumplimiento absoluto en el compromiso por la paz. Si bien apoyaron la firma del Acuerdo de Paz cuando llegaban los proyectos de ley los partidos de la $\mathrm{U}$, Cambio Radical y Liberal no ayudaban a hacer las mayorías necesarias, no iban a las sesiones, se iban o presentaban propuestas para modificar el espíritu de los acuerdos. Por números, solo con las mayorías de los partidos de gobierno se hubieran logrado mayorías, pero no lo hacían. No hacían lobby ni coordinaban los debates, esta tarea la mayoría la hacían por lo general el Polo y los Verdes, ya desmovilizadas las FARC la implementación no le importaba a la bancada del gobierno. Por eso muchas veces el Centro Democrático lograba imponer las mayorías, por la falta de unidad de la bancada del gobierno» (comunicación personal, Andrea Rincón, asesora UTL, agosto 8, 2018).

Finalmente, hay otros tres factores que también influyeron en el proceso de aprobación de los contenidos de los puntos 1 y 2. La corrupción, 
el transfuguismo y el clientelismo son instituciones informales que están incrustadas en los actores que conforman instituciones políticas como el Congreso. Están ubicadas en lo que se denomina las arenas más inaccesibles y menos transparentes, aunque fundamentales para el funcionamiento de las organizaciones (Portes y Smith, 2012). En el presidencialismo colombiano, si no se tienen en cuenta estas tres instituciones informales dentro de la estrategia es muy difícil llevar a cabo los cambios institucionales, pues se requiere de la intervención de fuerzas mucho más profundas y arraigadas, ya que «las instituciones no se revolucionan a sí mismas y las transformaciones institucionales más importantes dependen de los niveles más profundos, la cultura y la estructura social» (Portes y Smith, 2012, p. 18). A continuación, un fragmento que permite observar dicho fenómeno:

¿Cuáles factores cree usted que afectaron la aprobación del punto 2 en el Congreso?

Por lo general el gobierno cuando tiene un punto en la agenda que debe pasar ofrece mermelada a los congresistas, o sea, contratos en proyectos con altas sumas de dineros, pero como no le interesaba mucho el tema del Acuerdo de Paz pues no puso en práctica esta estrategia, no repartió mermelada y esto desincentivó a los congresistas. También influyó el escenario electoral que se veía venir, muchos partidos empezaron a voltearse [transfuguismo]. Por ejemplo, Cambio Radical veía el final del gobierno Santos y empezó a tomar distancia de Santos y se fue al lado del Centro Democrático. Los partidos pensaban más en las elecciones del 2018 en donde la paz no daba tantos votos. Eso fue una mezcla de falta de mermelada, el transfuguismo y futuras candidaturas (comunicación personal, Carlos Duarte, asesor UTL, agosto 10, 2018).

Al preguntar por el tipo de estrategias que tanto la bancada de gobierno como la del Centro Democrático habían llevado a cabo para lograr sus objetivos, el asesor Carlos Duarte respondió que «básicamente fueron dos: la primera era no hacerle mayorías en los debates, el quórum, y la segunda era presentar modificaciones que afectaban los acuerdos». Al ser un juego político de estrategias este sector aprovechó la falta de unidad en la bancada del gobierno para evitar que se lograran las mayorías en el Senado, esto gracias al número de senadores de este partido (20). Era una bancada numerosa a la cual se sumaba el Partido Conservador (18) y algunos senadores de Cambio Radical (9), lo cual es normal y dentro de las normas formales legislativas. Por su parte, Andrea Rincón, asesora del senador del 
Polo Democrático, agregó que una de las estrategias del gobierno fue no presentar al Senado algunas leyes que no eran necesario llevar, para lo cual usó la vía decreto de fuerza de ley y así evitó el riesgo de que se modificaran en el Senado. Al contrastar lo dicho por ambos asesores con los resultados en las votaciones en el Senado en los puntos 1 y 2 del Acuerdo, el ausentismo fue algo que estuvo presente en todas las sesiones. Se puede afirmar que las votaciones no superan los 62 votos de los 80 senadores que, en el papel, tenía la coalición del gobierno.

Gráfica 2. Resultados votaciones creación de titulación de baldíos punto 1 .
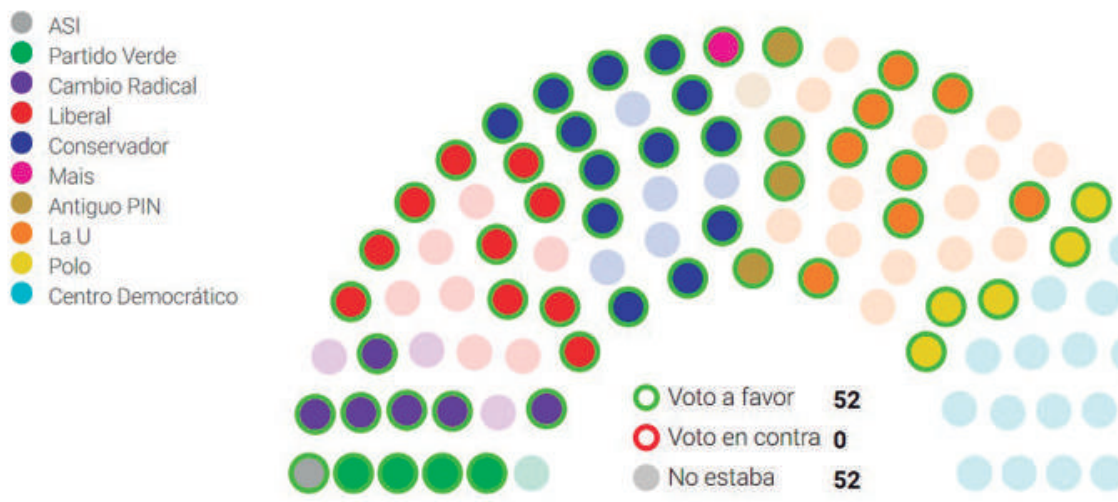

Fuente: tomado de Tatiana Duque (2017, mayo 19).

Gráfica 3. Resultados votaciones creación partido políticos de las FARC punto 2.
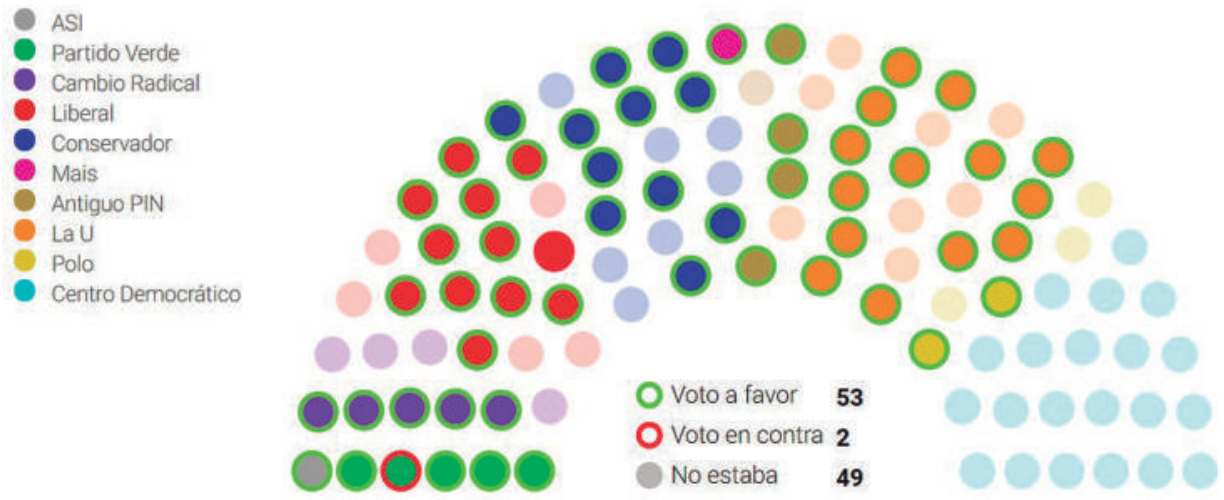

Fuente: tomado de Tatiana Duque (2017, mayo 19). 
El ausentismo, es decir, el hecho de no asistir a las sesiones del Senado o retirarse del recinto a pesar de haber atendido a los llamados a lista, fue la práctica más común del Centro Democrático. Esto se da debido a que no hay una reglamentación que castigue esta conducta. «El comportamiento de los actores políticos en el proceso de formulación de políticas [...] dependerá, a la vez, del funcionamiento de las instituciones políticas [...] y de las reglas institucionales básicas» (Scartascini et al., 2011, p. 15). De esta manera, al no haber la cantidad suficiente de senadores para realizar la votación era necesario levantar las sesiones; por otro lado, al asistir y retirarse también se impide que se complete el quórum. La unidad de mando del Centro Democrático le permitió al partido actuar en bloque de forma estratégica, lo cual conduce a señalar la consistencia y estabilidad de los partidos políticos como jugadores claves en todo proceso de cambio institucional, en este caso Álvaro Uribe Vélez — líder y fundador del Centro Democrático- tiene un partido cohesionado y disciplinado, caso contrario para Juan Manuel Santos.

Los partidos dominantes capaces de mantenerse alineados (en sistemas presidenciales, presidentes y legislatura del mismo partido, especialmente si el partido es el "centralizado») tienen la mayor capacidad para asegurar el apoyo legislativo para sus programas. Los gobiernos de coalición salen peor posicionados, y los sistemas presidenciales en los cuales el presidente y la legislatura representan a diferentes partidos tienen el mayor grado de dificultad para avanzar en la agenda legislativa (Scartascini et al., 2011, pp. 38-39).

Al final del periodo de Fast Track el balance fue el siguiente: se aprobaron once iniciativas de ley de cincuenta, entre las cuales están el Estatuto de la Oposición, las normas que reglamentan la Justicia Especial para la Paz reforma constitucional y ley estatutaria-, la seguridad jurídica para Voces de Paz, la Ley de Innovación Agropecuaria y la reforma constitucional de monopolio de armas; también culminaron su trámite la norma que buscaba blindar los acuerdos de La Habana por tres periodos constitucionales, la Ley de Amnistía y la reforma constitucional que garantiza las diez curules al partido de la FARC durante dos periodos constitucionales; se retiraron o archivaron tres proyectos, de los que se destaca la reforma electoral propuesta por la MEE (Pacifista, 2017, diciembre 13).

Con el hundimiento de la reforma electoral se perdió una oportunidad muy valiosa de cambiar la forma de hacer política en Colombia y de tratar de devolverles a los ciudadanos, al menos parcialmente, la confianza perdida en 
los partidos y los políticos. Fue ingenuo no advertir que es poco probable la aprobación en el órgano legislativo de una reforma que le afecta a sí mismo. Los congresistas no tienen ningún interés en modificar las reglas mediante las cuales fueron elegidos. En efecto, los legisladores carecen de incentivos para cambiar la certeza de un sistema electoral que conocen y manejan por la incertidumbre que representa un nuevo conjunto de normas. Los entrevistados señalan que la demora del gobierno en presentar los proyectos de ley al Congreso afectó la reforma al régimen electoral, ya que el gobierno dilató este punto y no se pudo discutir con tiempo. Las modificaciones que se hicieron a la reforma al régimen electoral en el Senado fueron de tal envergadura que los mismo partidos pro-paz y el gobierno decidieron archivarla, se convirtió en algo que nada tenía que ver con el espíritu de los acuerdos. El proceso de debate y aprobación no fue el óptimo, lo cual afectó claramente los resultados que se querían obtener: «El potencial de las recetas de política para lograr resultados positivos depende, en gran medida, de la calidad del proceso de formulación de las políticas a través del cual se debaten, se aprueban y se implementan» (Scartascini et al., 2011, p. 2).

Respecto a la reforma rural, el balance es el siguiente: puntos como la adecuación de tierras, la ley de titulación de baldíos en zonas de reserva forestal y el catastro multipropósito no alcanzaron a llegar al Senado por falta de quórum en la Cámara; faltó aprobar la modificación a la ley orgánica del Plan Nacional de Desarrollo, la normativa de los planes de desarrollo territoriales, el servicio público de adecuación de tierras, la ley de zonas de reserva forestal que se debía cambiar para posibilitar la actividad económica y tampoco se logró radicar a tiempo el proyecto de ley de tierras que modificaría aspectos de la Ley de Reforma Agraria de 1994. En conclusión, la reforma en el periodo del Fast Track quedó cruda debido a que es un tema con demasiados recelos por las posibles enmiendas que tergiversan los objetivos reales del Acuerdo de Paz.

\section{A modo de conclusiones}

Hay cuatro conclusiones que condensan los elementos más llamativos del estudio. La primera de ellas es que los cambios potenciales en las reglas políticas y en el acceso y uso de la tierra deben considerarse cuidadosamente, ya que estas reglas se ajustan dentro de configuraciones institucionales más amplias e históricas. Esta consideración fue tenida en cuenta a medias en la 
estrategia del Gobierno y de las FARC-EP, aunque el proceso de negociación fue arduo y lograron concertar sobre qué se debía acordar; no obstante, las fallas en la estrategia de implementación de los puntos 1 y 2 tienen vacíos en el cómo. Aunque el cambio institucional buscaba cambiar los arreglos de poder no se tuvo en cuenta el arraigo de estos arreglos, las profundas raíces en el sistema de valores y en la estructura social; sumado a esto, quedó por fuera del cálculo las dinámicas que implican dicho cambio en un régimen presidencialista.

La segunda conclusión es que el panorama preelectoral que se avecinaba y la falta de incentivos de los senadores fueron factores que debilitaron el poder político del Ejecutivo. Respecto a el primer factor, la estabilidad de las políticas en el presidencialismo colombiano depende de la capacidad de los actores políticos para acordar y hacer cumplir acuerdos; sin embargo, influye más la duración en el cargo de ciertos políticos. En escenarios donde el comportamiento cooperativo es más difícil de alcanzar y sostener, las políticas serán demasiado inestables o demasiado rígidas (Scartascini et al., 2011). El segundo factor es el poder dividido, el cual se presenta cuando el partido mayoritario o la coalición de partidos que dominan en el Parlamento es diferente a los intereses del Ejecutivo, lo cual provocó un permanente obstáculo a la gestión gubernamental, dándose roces entre el Ejecutivo y el Legislativo que dan como resultado la parálisis del cambio institucional. El resultado es el de un gobierno debilitado, que para poder sacar adelante sus proyectos se ve obligado ceder en aspectos claves del Acuerdo formando mayorías forzadas y débiles.

Esto último está estrechamente relacionado con la tercera conclusión, la dependencia de trayectoria, o sea, «la tendencia de los acontecimientos a seguir un curso rígido en el que «lo que existía ayer» determina en gran parte lo que ocurre hoy y lo que es probable que ocurra mañana en las instituciones» (Portes y Smith, 2012, p. 37). La trayectoria histórica específica de Colombia en materia de cambios institucionales señala que hay que tener en cuenta la capacidad de resistencia de ciertos ordenes sociales para impedir arreglos institucionales que brinden soluciones a problemas esencialmente políticos, como el acceso a la tierra y la participación política. Por tal razón, las posibilidades de una transformación real están asociadas a la profundidad de las reformas, la generación de un ordenamiento institucional nuevo y la lucha de clases o divisiones en las elites. 
Finalmente, es necesario tomar nota sobre los desafíos políticos de un proceso de paz que implica una transición política de largo aliento, una paz negociada. Más que pensar las negociaciones y acuerdos como algo lineal, que va del conflicto y termina en la paz, se trataría de centrar la mirada en las transformaciones de las relaciones en medio de conflictos históricos, en los cuales la negociación opera como un mecanismo o un arreglo institucional para el ajuste de las relaciones de poder (Renders y Terlinden, 2010). Son procesos heterogéneos, no lineales y continuos. También es necesario que este nuevo ordenamiento institucional logre resistir a los ataques del actual gobierno y otros sectores políticos, los cuales buscan que sus alcances no alteren sus intereses económicos, políticos y sociales, lo que permite que las reformas planteadas tengan la capacidad de penetración en el sistema de valores y normas de la sociedad colombiana.

\section{Referencias bibliográficas}

1. Albán Moreno, Álvaro. (2017). Instituciones y conflicto en Colombia: la metáfora del espejo. Ensayos de Economía, 27 (50), pp. 37-63. https://doi.org/10.15446/ede. v27n50.66520

2. Arévalo, Julián. (2014). Construcción de paz y un nuevo modelo de

[202] construcción de estado: una lectura de los dos primeros acuerdos de La Habana. Revista de Economía Institucional, 16 (30), pp. 131-169.

3. Basset, Yann. (2018). Claves del rechazo del plebiscito para la paz en Colombia. Estudios Políticos, 52, pp. 241-265. https://doi.org/10.17533/udea.espo.n52a12

4. Colombia. Presidencia de la República. Acto Legislativo 01. (7 de julio de 2016). Por medio del cual se establecen instrumentos jurídicos para facilitar y asegurar la implementación y el desarrollo normativo del Acuerdo final para la terminación del conflicto y la construcción de una paz estable y duradera. Recuperado de http:// es.presidencia.gov.co/normativa/normativa/ACTO $\%$ 20LEGISLATIVO $\% 2001 \% 20$ DEL\%207\%20DE\%20JULIO\%20DE\%202016.pdf

5. Duque, Tatiana. (2017, mayo 19). El ausentismo en tiempos del Fast Track. La Silla Vacía. Recuperado de https://lasillavacia.com/historia/el-ausentismo-en-tiemposdel-fast-track-60997

6. El Tiempo. (2016, noviembre 16). Los 10 momentos de tensión que marcaron la renegociación del Acuerdo. Recuperado de https:/www.eltiempo.com/politica/ proceso-de-paz/como-se-construyo-el-nuevo-acuerdo-de-paz-57008

7. El Tiempo. (2016, noviembre 17). Una reflexión para quienes votaron «No» en el plebiscito. Recuperado de https://www.eltiempo.com/politica/proceso-de-paz/ cuales-fueron-los-cambios-del-nuevo-acuerdo-de-paz-31308 
8. Evans, Peter. (2006). Desarrollo y cambio institucional: los escollos del monocultivo y las potencialidades de la deliberación. Revista SAAP, 2 (3), pp. 455-488.

9. Gobierno de Colombia y FARC-EP. (2016). Acuerdo final para la terminación del conflicto y la construcción de una paz estable y duradera. Oficina del Alto Comisionado para la Paz. Recuperado de http://www.altocomisionadoparalapaz.gov.co/procesosy-conversaciones/Documentos\%20compartidos/24-11-2016NuevoAcuerdoFinal.pdf

10. Granovetter, Mark. (2003). Acción económica y estructura social: el problema de la incrustación. En: Requena, Félix (ed.). Análisis de redes sociales. Orígenes, teorías y aplicaciones (pp. 231-269). Madrid: CIS.

11. Gutiérrez, Francisco. (2015). ¿Una historia simple? En: Comisión Histórica del Conflicto y sus Víctimas. Contribución al entendimiento del conflicto armado en Colombia. Recuperado de http://www.altocomisionadoparalapaz.gov.co/ mesadeconversaciones/PDF/Informe \%20Comisi_n \%20Hist_rica \%20del $\% 20$ Conflicto $\% 20$ y $\% 20$ sus $\% 20$ V_ctimas. $\% 20$ La $\% 20$ Habana $\% 2$ C $\% 2$ Febrero $\% 20$ de\%202015.pdf

12. Pacifista. (2017, diciembre 13). Guía para entender lo que se aprobó (y lo que no) en el "fast-track». Recuperado de https://pacifista.tv/notas/guia-para-entender-loque-se-aprobo-y-lo-que-no-en-el-fast-track/

13. Perilla, Deissy. (2018). La plebitusa: movilización política de las emociones posplebiscito por la paz en Colombia. Maguaré, 32 (2), pp. 153-181. https://doi. org/10.15446/mag.v32n2.77012

14. Portes, Alejandro \& Smith, Lori. (2012). Institutions Count. Berkeley: University California. https://doi.org/10.1525/california/9780520273535.001.0001

15. Portes, Alejandro y Sensenbrenner, Julia. (2012). Incrustación e inmigración: Apuntes sobre los determinantes sociales de la acción económica. Sociología económica de las migraciones internacionales. Madrid: Anthropos.

16. Renders, Marleen \& Terlinden, Ulf. (2010). Negotiating Statehood in a Hybrid Political Order: The Case of Somaliland. Development and Change, 41 (4), pp. 723746. https://doi.org/10.1111/j.1467-7660.2010.01652.x

17. Rincón, Andrés. (2018). De la esperanza a nuevas incertidumbres. Sobre la distribución de la votación en el plebiscito Colombia (2016). Análisis Político, 31 (92), pp. 137-158. https://doi.org/10.15446/anpol.v31n92.71104

18. Scartascini, Carlos; Spiller, Pablo T; Stein, Ernesto y Tommasi, Mariano (eds.). (2011). El juego político en América Latina: ¿Cómo se deciden las políticas públicas? Washington, D. C.: BID.

19. Semana. (2016, marzo 10). FARC pide no reconocer los resultados del plebiscito por la paz. Recuperado de https://www.semana.com/nacion/articulo/farcpide-no-reconocer-resultados-del-plebiscito-por-la-paz/496730 


\section{Julián Esteban García Romero}

20. Semana. (2016, noviembre 25). Así se refrendarán los acuerdos en el Congreso. Recuperado de https://www.semana.com/nacion/articulo/refrendacion-delnuevo-acuerdo-de-paz-con-las-farc-en-el-congreso/506632

21. Semana. (s. f.). Congreso 2014-2018. Recuperado de http://especiales.semana. com/especiales/congreso-colombia-2014-2018/

22. Trejos, Luis y Tuirán, Alberto. (2017). Debilidades institucionales en el nivel local. Desafíos de la gestión territorial de la paz. Análisis Político, 90, pp. 77-102. https://doi.org/10.15446/anpol.v30n90.68557

23. Uprimny, Rodrigo. (2007). La judicialización de la política en Colombia: casos, potencialidades y riesgos. Sur. Revista Internacional de Direitos Humanos, 4 (6), pp. 53-69. https://doi.org/10.1590/S1806-64452007000100004

24. Vega, Renan. (2015). Injerencia de los Estados Unidos, contrainsurgencia y terrorismo de Estado. En: Comisión Histórica del Conflicto y sus Víctimas. Contribución al entendimiento del conflicto armado en Colombia. Recuperado de http://www. altocomisionadoparalapaz.gov.co/mesadeconversaciones/PDF/Informe $\% 20$ Comisi_n\%20Hist_rica $\% 20$ del $\% 20$ Conflicto $\% 20 y \% 20$ sus $\% 20$ V_ctimas. $\% 20$ La $\% 20$ Habana\%2C\%20Febrero\%20de\%202015.pdf

25. Zamudio, Laura y Culebro, Jorge. (2013). Los procesos de implementación de los acuerdos de paz, aportes desde el nuevo institucionalismo. Análisis Político, 77, pp. 175-194. 